\section{Influencer Marketing from a Consumer Perspective: How Attitude, Trust, and Word of Mouth Affect Buying Behavior}

\author{
Kamaldeep Singh
}

Turiba University

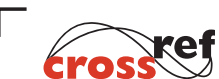

http://dx.doi.org/10.5755/j01.eis.1.15.28803
EIS 15/2021

Influencer Marketing from a Consumer Perspective: How Attitude, Trust, and Word of Mouth Affect Buying Behavior

Submitted 01/2021

Accepted for publication 06/2021

Abstract marketing brands. The purpose of the study has been to gain a deeper understanding of how social media influencers affect consumers' buying behavior. To understand this, consumers' attitudes and confidence in the phenomenon have been relevant factors to examine. The study also aimed to find out whether Word of Mouth (WoM) or social media influencers have the greatest impact on consumers' buying behavior. The results have shown that social media influencer's impact on consumers' buying behavior depends on whether attitudes are positive or negative. Consumers with positive attitudes towards social media influencers have a greater tendency to acquire what is marketed in comparison with consumers who have negative attitudes towards social media influencers, who instead refrain from buying. Factors that increase confidence in social media influencer are whether the consumer feels connected, honesty and that social media influencer in markets products / services within its area of expertise. What has been shown to play a significant role when it comes to influencing consumers' buying behaviors and attitudes is what the environment's perceptions, opinions and experiences about the phenomenon look like WoM. It has emerged that the respondents have a greater confidence in their surroundings than they have in social media influencers.

This study will adopt a qualitative approach towards collection and analysis of data. Hence this study will investigate influencer marketing from a consumer perspective through a qualitative method with the help of semi-structured interviews. The researcher will conduct a minimum of 5 semi-structured interviews and analyze the data to formulate the required findings of this study.

KEYWORDS: atitude, buyer behavior, social media influencer (SMI), impact, trust, Word of Mouth (WoM).

Since the beginning of the internet, the world has changed a lot. It started as a place there web pages were created for the purpose of informing to a place where internet users can create themselves content. According to a report from the Internet Foundation (2016), 53\% of internet users are on at least one social media since 2010 in one way or another. Social media is described as Internet-based technical applications based on Web 2.0 and which allows the creation and exchange of content created by users. The term Web 2.0 first began to be used in 2004 for the purpose of describing platforms where content is no longer created and published by individuals, but changed continuously by all users in different ways. There are many different types of social media, some of which are YouTube, Instagram, Facebook and Snapchat.

Social media users have the opportunity to share their views. Balakrishnan et al. (2014) write that social media influencers (SMI) are social media users who have created a kind of credibility in a specific industry through his activity on social media. These SMls have access to a large group
Introduction

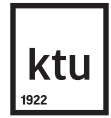

European Integration Studies No. 15 / 2021, pp. 231-241 doi.org/10.5755/j01.eis.1.15.28803 
of people who regularly follows SMI's activity on social media and in general SMIs are perceived by others users as credible (Ki et al., 2019). To unlike celebrities or public figures that have become known through traditional media is SMls are usually people who have created sympathetic online personalities and are very visible for its followers through the creation of viral content on social media (Lou \& Yuan, 2019). SMls are considered to be human brands using their platform to present their ideas; photos, their expertise and sponsored products (Taillon et al., 2020). The sponsored posts published by SMls are exchanged for Compensation Company or brand that the post is sponsored by (Campbell \& Farrell, 2020). This is called for influencer marketing and is about companies using SMls to promote consumers' brand awareness and influence their purchasing decisions via social media. Influencer marketing is a type of viral marketing where SMI shapes consumers' attitudes through posts on their social media (Freberg et al., 2011).

Technological developments have influenced consumers' preferences and behaviors. Factors that change consumer behavior in the market are technological development, access to different choices, trends in society and improved economy of the population. Consumers are becoming more and more informed because of the internet, which does it is more difficult to influence consumers via traditional media. Social media has contributed to consumers changing their consumption habits by giving consumers a new way of finding, judging and choosing different goods and services. Lou and Yuan (2019) write that mass communication channels such as television, radio and newspapers are no longer dominant sources for consumers to find information on. Instead, consumers use social media or virtual communities for information exchange and relationship building, which are channels that SMIs use This has led to social media in recent years has become a significant advertising platform that enables brands to reach out to consumers via the internet. Lou and Yuan (2019) believe that the most important factors are the relationship between the consumer and SMI and the credibility of SMIs. Based on the previous research presented, the information on how Consumer behaviors are affected by influencer marketing deficient in several respects on how a source's credibility affects consumers' attitudes, buying intentions and actual buying behaviors in contexts other than traditional media. The information is also deficient in that previous studies have mainly studied how SMls work electronic WoM can influence consumer behavior, hence the interest in exploring how traditional WoM is influences buying behaviors in relation to influencer marketing. With that said, it is relevant that fill this research gap by reviewing the attitudes and trusts of consumers SMI and how these factors affect buying behavior as well as examine how traditional WoM is affects consumers in connection with influencer marketing.

The aim of this study is to gain a deeper understanding of consumers' attitudes towards the phenomenon of influencer marketing and how this in turn affects buying behavior. To understand Consumer attitudes, it is of great importance to find out how their trust in social media influencers looks like. The study also aims to find out whether WoM or SMls have the greatest impact on consumer buying behavior.

\section{Credibility}

That companies use influencers as a complement to their other marketing has become increasingly common. Studies from 2019 show that influencers' credibility, attractiveness and similarity to its followers tends to both create brand awareness and increase brand value (Jiménez-Castillo \& Sánchez-Fernández, 2019). What counts as an influencer? An influencer is a person who mainly acts and moves on social media, and has an influence or an opportunity to influence what people behavior or purchase intentions (Brown \& Fiorella, 2013). On social media, these people translate into followers. The one has the ability to influence other people can be anything from 
"celebrity" to "Micro-influencer". The goal of influencer marketing is for companies to spread their message in a credible way through these people who then previously holds a high level of trust among his followers (Cooley \& Parks-Yancy, 2019). Influencers communicate with their followers in a genuine way which results in them in turn interacting with the influencers content and engage with the information by, for example, liking, commenting, save and forward the content to their friends. These activities are called engagement and are a variable that determines how effective an influencer is for marketing purposes (Hughes et al., 2019). As a company, choosing to collaborate with the person with the largest following may seem like it influence on their followers compared to traditional "celebrities" in terms of trust and experience of a more personal contact (Djafarovaand Rushworth, 2017; De Veirman et al., 2017). Influencers who collaborate with companies on social media thus have a greater chance of implement a profitable campaign, thus not saying that the issue of size no longer plays any role as soon as it is moved to social media. Minor influencers, such as micro influencers, on the other hand, tend to have more successful campaigns in promoting divergent products, as their following is based on a more intimate form of loyalty and trust (Oliveira et al., 2019). Another study from 2017 shows, for example, that micro influencers with 1,000 followers generate about four percent more engagement per post than the influencers' more 10,000 followers (Dinesh, 2017).

\section{Word of Mouth (WoM)}

Trust plays a central role in the buying process as consumers specifically seek experience and credibility of goods or services (Grabner-Kraeuter, 2002). Morgan \& Hunt (1994) defines trust as trust in an exchange partner's reliability and integrity (Schlesinger et al., 2016). Reliability and integrity in this context are associated with consistency, competence, honesty, justice, responsibility, helpfulness and kindness. Grabner-Kraeuter (2002) believes that there are many consumers who are skeptical of e-commerce functional mechanisms, its processes and effects as well as the quality of the goods offered on the Internet. This may be because the consumer has no experience of or does not consider e-commerce being credible. The recipient is the one who feels trust while credibility is found at the sender. Hence, the study uses both concepts, confidence to understand what in the recipient that makes it feel trust and credibility to understand what the user must have in order for it to be perceived as credible.

A source's credibility is based on the communicator's reliability, attractiveness and expertise (DjafarovaandRushworth, 2017). Lou \& Yuan (2019) also mention that it is more likely that consumers accept or trust SMI's views when they work with brands that are related to SMI's personal expertise. This means that an SMI that For example, having knowledge in makeup becomes more credible when reviewing a makeup-related product or service. Lee \& Kim (2020) believe that the brand's credibility and SMIs Credibility affects how consumers respond to advertising. This can mean that of the brand reputation in the market and that the consumer sees that the post that SMI posted is sponsored by the brand influences the consumer's response to advertising. According to Djafarova and Rushworth (2017) Consumers perceive individuals with a larger following as more attractive and credible. A built-up trust between consumer and company contributes to very positive results for the company such as loyalty to the company, repeat customers and product choices.

Marôpo et al. (2020) believe that due to YouTubers, SMls on the platform YouTube, shares their experiences, feelings and opinions, they create trust in their followers. This also explains why mainly teenagers can more easily relate to these micro-celebrities (SMI) which they follow in contrast to traditional celebrities from, for example, the film industry. Youtubers are perceived as equal and reliable than theirs personal stories make them seem accessible and credible. That 


\section{Methodology}

Findings and Analysis they are perceived on this way also has to do with the fact that they can easily interact with their followers but also that SMI usually be close in age with their followers, which means that SMI is considered capable of creating content which suits the followers. Lou \& Yuan (2019) mention one earlier study shows that consumers can have as much confidence in SMIs as in their friends.

The primary data in the study were collected using semi-structured interviews. Semi-structured interviews are the interview technique most used in qualitative research (Kallio et al., 2016). Kallio et al. (2016) believe that this is due to the interview format has proven to be both versatile and flexible. In semi-structured interviews the interviewer uses an interview guide that touches on various topics that are relevant to purpose of the study (Bell et al., 2018). To be able to take part in the reality of consumers Interviews were used in the study in order to find out how the research subjects perceive the phenomenon of influencer. Interviews allow the subject to participate in a discussion there the person shares their lived reality, which gives the researcher an opportunity to experience reality as the person does. One of the main benefits of the form of the interview is that it thus enables reciprocity between the interviewer and the respondent (Bolderston, 2012). This thus leads to the interviewer having the opportunity to ask follow-up questions based on the respondent's answer at the same time as it gives the respondent space to express their own self. A total of 13 interviews were conducted, of which eight were online interviews and five were telephonic interviews. The interviews lasted until theoretical saturation was achieved.The theoretical saturation was considered to have been met when the data collected had been sufficient to be able to be analyzed on the basis of the theoretical framework and to be able to answer the study research questions.

Results and analysis have been divided based on the study's theoretical framework which includes attitude, subjective norm, credibility and WOM. The collected data has been compiled and reported by reviewing how the negative and positive attitudes affect how individuals perceive one phenomenon. But also how WOM and the subjective norm affect consumers' attitudes and purchase intentions as well as the factors that make individuals feel confident in SMIs.

\section{Attitude}

Because the purpose of the study is to understand consumers' attitudes and buying behavior towards influencer marketing, it was considered of great importance to examine consumer attitudes. As As mentioned earlier, attitudes are a crucial factor in consumer behavior. When asked how the respondents perceive the phenomenon influencer marketing, according to the respondents. The majority of those with different attitudes believe that the positive thing about influencer marketing is that it is one way for those to be informed about for the unknown or new products.

"I think it's good that they do and I can get new ideas on what I can buy." - Respondent 3

"... I think it's good because through them you can partake of much and much as you may not have discovered, I kind of do not watch TV to enjoy a new product or any new post. "- Respondent 5

Respondent 4 describes influencer marketing as a win-win situation because it often in In connection with an SMI marketing something, discount codes are offered to the followers. Also respondent 2 and 3 mention that it is positive because discount codes are usually offered when SMI markets products. Respondents 1 and 5 themselves consider that they have no negative attitudes versus influencer marketing. However, both respondents 2 and 4 mention that they are aware of that SMI advertises to get money. Respondents 3, 4 and 9 believe that influencer marketing is positive because they receive information and are informed about, for example, new products. 
Seven of the respondents mention that they believe that SMI mainly advertises to make money on that. Of these seven respondents, respondents 2, 4, 5, 8, 10 and 12 feel that SMI has to say if a product is not genuine because it makes money from marketing the product. Several of the respondents mention that they are unsure whether the product actually works as SMI describes it. Respondents 1, 6 and 13 believe that there are other negative aspects with influencer marketing such as that it can create class gaps in society and that it leads to overconsumption and that they engage in surreptitious advertising.

"The negative is that it can lead to purchasing power and overconsumption because you might only buy to take advantage when you get a discount code even though you do not need it." - Respondent 1

"I consider this to be a negative aspect as it leads to more people feeling compelled to achieve certain goals to please others in their environment, even if they do not have the assets or the means to do so. I think this creates social divisions. It puts pressure on young people who grow up and mainly seem to be the target group where influencers reach out, regardless of the truth or falsehood of the product or marketing." - Respondent 6

Respondents 13 and 7 believe that influencer marketing can be annoying if it happens too a lot of advertising.

The question regarding what the respondents think when they see an influencer marketing a product or service was answered by all respondents. The majority of respondents convey that there is a concern that SMI does collaborations and advertising for companies only to get paid and that their reviews of the products thereof do not become credible or genuine. Concepts genuine and credible are a recurring word that many of the respondents used when answering the question. Many of these respondents thus feel that SMI does not actually use the product or know if it actually works.

"The first thing I think about is if this person actually uses the product and that they have received payment for marketing the product, i.e. if the influencer is credible." - Respondent 2 "Companies get their message out through the influencer and the influencer in turn gets paid to perform these advertisements. This makes me even more skeptical of them, as the content of their advertising does not can be classified as credible." - Respondent 6

"But most of the time it does not feel completely genuine, which really all types of advertising in my opinion do not feels."- Respondent 10

Respondents 4, 5, 9 and 12 believe that they may be attracted and interested when they see an $\mathrm{SMl}$ as advertise. Respondents 3 and 13 describe it as not being influenced by influencers marketing and that they do not think anything special when they see an influencer advertising.

The last question asked in relation to the theme of attitude was whether consumers will be more influenced to buy a product or service if it is a popular influencer made the advertisement. Respondents 2, 6, 8, 9 and 11 claim that they had been influenced by advertising from a popular SMI because they are probably a person who can themselves like and look up to which leads to that probably trust the person. They also mean that it is an SMI that you like coming the person most likely to advertise products that will interest you the followers. These respondents therefore believe that they had probably bought products from an SMI which they like. Respondents 3, 12 and 13 believe that they can be affected by the fact that it is a popular one influencer but that whether it will lead to a purchase depends mainly on other factors. Respondent 3 says that it had only been affected by this by having previous experience and further product information. Respondent 12 who believes that it depends on how the advertisement is designed and how the products are reported says: 
"It probably depends on how they market the product. Rebecca Stella is one of the influencers I follow and like and she usually advertises things and at the same time show different videos how to apply or use the product. This makes me more interested and maybe even gets me that product."

Respondent 13 claims that it may be affected depending on what kind of product it is but that in the person's age, it does not matter how popular an SMI is. Respondents 1, 4, 5, 7 and 10 state that they are not affected by how popular SMI is, but it depends on their own judgment of SMI, the need for the product and find out other information about the product.

"No, certainly not If it's not something I really like or need or not interested in, I will not buy it no matter who markets it." - Respondent 1

"If I feel like it's honest and not just doing this for the money, this is where I fall, I'm does not fall for how popular it is." - Respondent 7

\section{Credibility}

Because trust plays a central role in the buying process and the study examines how buying behavior affected, it was of great importance to examine how consumer confidence in the phenomenon looks. The first question in the theme of trust was whether consumers had bought something like marketed by an SMI. Respondents 1, 3, 4, 5, 7, 9 and 10 say they have bought someone or some products marketed by an SMI. The main reasons given by the respondents 1 , 3, 4 and 5 mention why they bought the product is that they either heard a lot about the product from several places or that SMI has offered a discount code in connection with its marketing.

"Yes, I bought X-brown (eyelash extender), but have not used it long enough for to be able to give a rating on the purchase itself. But from other people's feedback, it should have helped and worked. It remains to be seen what I think." - Respondent 4

"That I then got to see an influencer advertise and also give a discount code on that product led to a purchase." - Respondent 3

The remaining respondents who bought a product marketed by an SMI believe that it is the very marketing that SMI did that led to them becoming interested and attracting them the purchase. Respondents 2, 6, 8, 11, 12 and 13 have not accepted any offer as an SMI advertised for. Both respondents 11 and 13 believe that they have not accepted any offer because they do not follow any SMI on their social media. Respondent 8 says that it did not buy somewhat because it is a bit skeptical of influencer marketing regarding how credible SMls really are. Respondent 2 claims that it did not receive any offer due to that the products or services that SMIs usually market do not interest the person.

The second question in the theme of trust was asked to find out what makes consumers feel credibility for SMI. Respondents' views on what makes them feel that one SMls are credibly varied. Respondents 2, 6, 7 and 9 believe that it is necessary to know someone community or affiliation with $\mathrm{SMI}$ and that one follows the person and perhaps followed the person for a longer period. This affiliation or community can be, for example similar interests. Other respondents who had similar responses were 4, 5, 10 and 12 believe that the person becomes more credible if it shows the products and their properties but also that SMI himself tested it and can convey his honest opinion. The respondents believe that SMI can do so in such a way that it shows, for example, before and after the result of the product or what it contributed with.

"On the other hand, is it skin care that the person himself tests and posts videos and maybe even and with a result, this can make the influencer more credible." -Respondent 5

Respondents 5, 11 and 13 believe that an SMI that markets products within its own area of expertise becomes more credible. 
"If it has knowledge of what it markets, it feels more credible." - Respondent 11

Respondents whose answers were not the same as anyone else's were 1, 3 and 8. Respondent 1 believes that an SMI will be reliable if it raises both the positive and negative in its marketing aspects of the product or service so that it does not just feel like the person is getting paid to speak well of the product. Respondent 3 says that it is difficult for an SMI to be credible in its advertising as it gets paid for it. Last but not least respondent 8, who believes that it could be more credible if several SMIs advertised the same product or service. The respondent also means that it probably would have played if SMI had made collaborations with a company for a longer period and that if it is a larger company that is behind the product marketed.

The third question was whether it matters to the respondent what type of influencer it is. The question is intended to investigate whether consumers feel more confident in, for example, one larger or smaller SMI. The majority of respondents believe that it does not matter how big a SMI is. The main factors that seem to play a role for these respondents are about they are honest in their marketing, affiliation with SMI and whether SMI advertises products within their own expertise.

"There is one that I follow who is very big Jon Olsson, sometimes when he recommends one camera, it was the camera I mentioned earlier that I bought and I have bought it since he knows this with cameras and knows what he is doing and that was why i felt $i$ could trust on him "- Respondent 7

Respondent 12 believes that what actually matters is the person's own about an SMI. Respondent 8 conveys that it can both play a role but at the same time that it does not have to. The respondent describes it as follows:

"Yes it does matter I would probably consider a bigger profile as more credible. I was probably attracted more of a larger profile that markets something than one that has type 100 followers... fixed at the same time type still maybe not, it might feel more authentic if there is any smaller profile like market something other than these biggest profiles that do. Because it feels like the bigger ones the profiles may be more bought by companies. "

Respondents 2, 3, 11 and 13 state that how big an influencer is matters. The respondents believe that larger SMIs feel more reliable because they believe that a larger SMI cannot just lay up anything and that there is a reason why the person is so great on social media.

"Yes it does, it feels credible if the person has more followers. I think one with so many followers do not have followers just because there is something interesting about the person." - Respondent 11

The last question that deals with the theme of credibility is: in what way does the brand affect you which an influencer advertises for? Respondents 1, 2, 3, 4, 7, 8, 9 and 11 say that a larger brand plays a certain role in their for their buying intentions. Respondents 1, 2, 3 and 4 mean that a brand that is well known makes them feel safe because they feel they have both more knowledge and can search for information about the product being marketed. They mean too that a well-known brand feels more reliable because it is already established in the market. Respondents 4 and 9 also say that it feels more reliable because you yourself may have had it before brand experience. Respondents 6, 10 and 13 claim that the brand itself does not play a role without what matters is SMI's credibility and previous experience. Respondent 5, 7 and 12 says that if an SMI markets a new product, it may interest the person but that it still chooses to read about the product on the internet. 


\section{WOM}

Word-of-Mouth highlights how consumers can be affected by other people giving theirs opinions about a purchase. This aspect is important to investigate as we as researchers get a deeper look insight into how consumers' buying behaviors can be shaped by the recommendations of others. When asked if the respondents know anyone who has bought an item due to influencers marketing, everyone answers yes except respondents 5, 6, 12 and 13 who say they do not know anyone who have bought something through influencer marketing. The remaining 9 respondents who answered yes the question also received a follow-up question where they had to answer whether the person has shared theirs experiences around the purchase. Respondents 2, 8 and 9 answer that they know people who have bought products via influencer marketing, but that they do not really remember what it was and therefore could not answer on the follow-up question. Respondents 1 and 3 say that they can be more influenced to a purchase when it comes to the opinions of others. Respondent 3 believes that if a person had recommended one product or service, it would have had a positive effect on them.

"The person has talked about their experience of the purchase and thought that the product was very good and recommended product. The product was not something that interested me so that's why I was simply interested in buying it, but had it been something else that interests me the person's judgment had affected me." -Respondent 1

"Yes, my husband bought a pair of wireless headphones because his favorite football player was advertising for them. Maybe not an influencer, but someone he looked up to who influenced him to one buy. He was a little disappointed as the quality was not the best, but they were still good. He was satisfied in the end." -Respondent 4

Respondent 7 answers that someone in her vicinity traveled to a holiday resort due to a influencer advertised the destination. The person in question had nothing negative to say about themselves the experience.

Respondent 10 believes instead that there are some in the area who bought things like marketed by influencers, not because they are influenced by the influencer itself but because it has existed an interest in the product it and those influencers have given away discount codes.

The next question within the WOM theme was asked to find out whether the respondents themselves had advised against it or recommended an item marketed by influencers. The answers collected show that respondents 1,2 and 7 have given recommendations for products that they themselves have been satisfied with thanks to influencer marketing.

"Yes I have. It was soap for the face, there are a few different types that are adapted for different skin types so I recommended this for one person because I thought it would fit persons. The person became interested but I think she may not have thought it was so affordable" - Respondent 1

Respondent 3 replies that she did not make recommendations based on influencer marketing, however generally believes that if there is something she considers to be happy with, she recommends it the product. Especially if she knows that someone in the area has been looking for a product like herself had good experiences of.

Respondents 4, 9, 10 and 12 answer that they absolutely recommend or advise people in their environment if they themselves have their own experience of the product. The respondents highlight also in their response that it does not only apply to products purchased due to influencer marketing, without products of which they have experience in general. Is it a product that they know people in their surroundings are interested in and have their own experiences around that product, says respondents that they are honest about whether it was positive or negative. 
Respondent 5 believes that she is not affected by influencer marketing and says that if it is something that she herself is interested in, her own information search will be made for it. Respondents $6,8,11$ and 13 say that they have not bought anything as an influencer marketed and therefore they have not been able to express their views on that issue.

When it comes to the question of how respondents are affected by someone around them had positive or negative experiences about influencer marketing is a result of respondents' answers in chapter 4.2. This question will also be analyzed based on the WoM theory as it intends to find out how the opinions of others affect other people.

As previously mentioned, the respondents are influenced by what people around them have to say. Respondents 1, 2, 3, 4, 5, 7, 8, 9, 11 and 13 say that they had probably avoided buying something if they heard negative opinions about products just as they had become more interested of positive opinions given by someone around them, this because they have a larger trust in them.

Respondent 7 answers: “... with both positive and negative experience, I want to take part in the reasons why the experience was as it was. I want to investigate it myself but also take part in other people's opinions to decide."

Respondent 12 believes instead that there is of course an impact when it comes to positive or negative opinions, but that it is they who decide whether to buy something or not even if it may be that it has been perceived as negative by others.

"Probably depends on what it is as some people may have different opinions on products that do not fit them, but which might have suited me. It probably depends a lot on what it is and how bad / good their own experiences are."- Respondent 12

The results show that confidence in influencer marketing looks different depending on how people's attitudes towards the phenomenon look like. Previous studies on the phenomenon have emerged that the reason why consumers follow SMls is because they share similar interests with SMI, that you feel some community with the person and how reliable the person is. What we have come to in this study is what consumers get to feel confident in SMIs is belonging to the person, to feel that the person is honest and that the person has expertise in what it markets. Previous studies also show that Consumers with positive attitudes towards an SMI would generally intend to buy a product that SMI markets, which has also emerged in this study then most consumers who have positive attitudes towards the phenomenon also have took part or could take part in offers marketed by SMls. In the same way leads to negative experiences and negative attitudes of influencer marketing to a reduced trust and interest in SMls, which contributes to consumers not wanting to take part in what offered and refrains from buying. The study shows that WoM has a major impact on consumers buying behaviors when trust in the environment is greater than trust in SMls. This is because that the WoM receiver has a type of relationship with the WoM transmitter (family, relatives, friends, etc.). Consumers therefore prefer to listen to the recommendations of those around them than to SMls recommendations. That the opinions and recommendations of the environment have a great conviction and the impact on consumers' buying behavior also appears in other studies that believe that The WoM transmitter is considered credible as they are usually independent of the product / service and not seeks to influence the WoM receiver to its advantage.

The problem that can arise with the fact that there is an overrepresentation of women in the study is that the results cannot tell if these perceptions are present in the whole population, social media users in India, so the selection will not be representative. Based on the conclusions, we can see that there are certain tendencies for phenomena in the sample which means that these perceptions may also be present in the population. What the results show is that men seem to 
have one more negative attitude towards the phenomenon while women seem to look at the phenomenon on a more positive way. And that the women are the only ones who bought something marketed by an SMI.

These conclusions can contribute to the improvement of existing marketing strategies influencer marketing. The conclusions can help the companies that use influencers marketing to be able to understand how to build trust and achieve positive attitudes of the audience this by being aware as a company that WoM affects consumers very much in their purchasing decisions (Bataineh, 2015). By being aware of this it is important as a company to live up to what is marketed so that it does not arise negative consumer experiences. As a company, it is also important to work with SMls that possess an expertise in what to market for consumers to feel confidence in advertising. The conclusions can also be of great help to these SMls so that they can focus on advertising products within their own area of expertise as it has been an important one factor for consumers to feel confident. They can also design their advertising and portray themselves according to the factors that form positive attitudes among consumers such as offering discount codes. The study also intends to contribute to further research in influencer marketing, consumer behavior in relation to influencer marketing and SMI and how they affect consumers. We believe that further research in this area is required as this phenomenon is still relatively new, which, as previously mentioned, leads to new buying behaviors.

Balakrishnan, B. K. P. D., Dahnil, M. I., \& Yi, W. J. (2014). The Impact of Social Media Marketing Medium toward Purchase Intention and Brand Loyalty among Generation Y. Procedia - Social and Behavioral Sciences, 148, 177-185. https://doi.org/10.1016/j.sbspro.2014.07.032

Bataineh, A. Q. (2015). The Impact of Perceived e-WOM on Purchase Intention: The Mediating Role of Corporate Image. International Journal of Marketing Studies, 7(1). https://doi.org/10.5539/ijms.v7n1p126

Bell, E., Bryman, A., \& Harley, B. (2018). Business research methods. Oxford university press.

Bolderston, A. (2012). Conducting a Research Interview. Journal of Medical Imaging and Radiation Sciences, 43(1), 66-76. https://doi.org/10.1016/j. jmir.2011.12.002

Brown, D., \& Fiorella, S. (2013). Influence marketing: How to create, manage, and measure brand influencers in social media marketing. Que Publishing.

Campbell, C., \& Farrell, J. R. (2020). More than meets the eye: The functional components underlying influencer marketing. Business Horizons, 63(4), 469-479. https://doi.org/10.1016/j.bushor.2020.03.003

Cooley, D., \& Parks-Yancy, R. (2019). The effect of social media on perceived information credibility and decision making. Journal of Internet Commerce, 18(3), 249-269. doi.org/10.1080/15332861.2019.1595362

De Veirman, M., Cauberghe, V., \& Hudders, L. (2017). Marketing through Instagram influencers: the im- pact of number of followers and product divergence on brand attitude. International Journal of Advertising, 36(5), 798-828. https://doi.org/10.1080/026504 87.2017 .1348035

Dinesh, D. (2017) Why Micro-Influencers are a Social Media Marketing Imperative for 2017.

Djafarova, E. \& Rushworth, C., (2017). Exploring the credibility of online celebrities' Instagram profiles in influencing the purchase decisions of young female users. Computers in Human Behavior, 68, pp.1-7. doi.org/10.1016/j.chb.2016.11.009

Freberg, K., Graham, K., McGaughey, K., \& Freberg, L. A. (2011). Who are the social media influencers? A study of public perceptions of personality. Public Relations Review, 37(1), 90-92. https://doi. org/10.1016/j.pubrev.2010.11.001

Grabner-Kraeuter, S., (2002). The role of consumers' trust in online-shopping. Journal of Business Ethics, 39(1), pp.43-50. doi.org/10.1023/a:1016323815802

Hughes, C., Swaminathan, V., \& Brooks, G. (2019). Driving Brand Engagement Through Online Social Influencers: An Empirical Investigation of Sponsored Blogging Campaigns. Journal of Marketing, 83(5), 78-96. https://doi.org/10.1177/0022242919854374

Jiménez-Castillo, D., \& Sánchez-Fernández, R. (2019). The role of digital influencers in brand recommendation: Examining their impact on engagement, expected value and purchase intention. International Journal of Information Management, 49, 366-376. https://doi.org/10.1016/j.ijinfomgt.2019.07.009 
Kallio, H., Pietilä, A.-M., Johnson, M., \& Kangasniemi, M. (2016). Systematic methodological review: developing a framework for a qualitative semi-structured interview guide. Journal of Advanced Nursing, 72(12), 2954-2965. https://doi.org/10.1111/ jan.13031

Ki, C. "Chloe", \& Kim, Y. (2019). The mechanism by which social media influencers persuade consumers: The role of consumers' desire to mimic. Psychology \& Marketing, 36(10), 905-922. https://doi. org/10.1002/mar.21244

Kim, S. J., Pai, S., Bickart, B. A., \& Brunel, F. F. (2014). How Social Media Influencers Build a Brand Following by Sharing Secrets. Boston U. School of Management Research Paper Vol. 2549040, pp. 23. https:// doi.org/10.2139/ssrn.2549040

Lee, S., \& Kim, E. (2020). Influencer marketing on Instagram: How sponsorship disclosure, influencer credibility, and brand credibility impact the effectiveness of Instagram promotional post. Journal of Global Fashion Marketing, 11(3), 232-249. https:// doi.org/10.1080/20932685.2020.1752766

Lou, C., \& Yuan, S. (2019). Influencer Marketing: How Message Value and Credibility Affect Consumer Trust of Branded Content on Social Media. Journal of Interactive Advertising, 19(1), 58-73. https://doi.org/ 10.1080/15252019.2018.1533501
Marôpo, L., Jorge, A., \& Tomaz, R. (2019). "I felt like I was really talking to you!": intimacy and trust among teen vloggers and followers in Portugal and Brazil. Journal of Children and Media, 14(1), 22-37. https:// doi.org/10.1080/17482798.2019.1699589

Morgan, R. M., \& Hunt, S. D. (1994). The Commitment-Trust Theory of Relationship Marketing. Journal of Marketing, 58(3), 20. https://doi. org/10.2307/1252308

Oliveira, M., Barbosa, R., \& Sousa, A. (2019). The Use of Influencers in Social Media Marketing. Smart Innovation, Systems and Technologies, 112-124. https://doi.org/10.1007/978-981-15-1564-4_12

Schlesinger, W., Cervera, A., \& Pérez-Cabañero, C. (2016). Sticking with your university: the importance of satisfaction, trust, image, and shared values. Studies in Higher Education, 42(12), 2178-2194. https://doi.org/10.1080/03075079.2015.1136613

Taillon, B. J., Mueller, S. M., Kowalczyk, C. M., \& Jones, D. N. (2020). Understanding the relationships between social media influencers and their followers: the moderating role of closeness. Journal of Product \& Brand Management, 29(6), 767-782. https://doi.org/10.1108/JPBM-03-2019-2292

Young, K., (2017). Social Media Captures Over 30\% of Online Time. GlobalWeblndex.

\section{KAMALDEEP SINGH}

\section{Ph.d Student}

Turiba University

\section{Fields of interests}

Business Administration.

\section{Address}

Graudu iela 68b, Riga LV-1058, Latvia

kampreet0001@gmail.com 